\title{
The role of methicillin-resistant Staphylococcus aureus in clinical infections in Obafemi Awolowo university teaching hospitals complex, lle-Ife, South Western Nigeria
}

\begin{abstract}
This study determined the prevalence of Methicillin-resistant Staphylococcus aureus (MRSA) from 246 clinical samples collected at a tertiary care hospital, its antimicrobial susceptibility, spectrum of infections and the associated risk factors. Standard procedures were used for isolation, screening, and susceptibility testing. The result showed that 41 $(40.2 \%)$ out of $102 \mathrm{~S}$. aureus isolated were methicillin-resistant while $61(59.8 \%)$ were methicillin-sensitive. The prevalence rate of MRSA for male and female group was 37.3\% and $43.1 \%$ respectively. Thirty $(73.2 \%)$ methicillin-resistant $S$. aureus isolates were obtained from inpatients while $11(26.8 \%)$ were from outpatients. MRSA were significantly isolated from the Orthopaedic ward $(\mathrm{OR}=3.36 ; \mathrm{P}=0.031)$ and the antenatal ward $(\mathrm{OR}=8.33$; $\mathrm{P}=0.037)$. High resistance rates were exhibited by MRSA isolates to cefotaxime (102, $79.4 \%)$ and clindamycin $(102,49 \%)$ but had low resistance rates to gentamicin $(102$, $27.5 \%)$ and chloramphenicol $(\mathrm{n}=102,28.4 \%)$. MRSA were more significantly resistant to gentamicin $\left(\chi^{2}=12.284 ; \mathrm{p}=0.0001\right)$, clindamycin $\left(\chi^{2}=20.234 ; \mathrm{p}=0.0001\right)$ and cefotaxime $\left(\chi^{2}=13.812 ; \mathrm{p}=0.0002\right)$ than MSSA. Thirty-two $(78 \%)$ out of 41 MRSA isolated were multidrug resistant. All isolates (MRSA and MSSA) were susceptible to vancomycin with MIC values ranging from 2.1 to $0.12 \mu \mathrm{g} / \mathrm{ml}$. This study showed a high prevalence of MRSA in clinical infections that were resistant to treatment options in OAUTHC, Ile-Ife. Being in the antenatal and orthopaedic wards is a predictor of MRSA infections in the hospital. In spite of reports that vancomycin resistant Staphylococcus aureus is increasing, it is yet to be a problem in the hospital and vancomycin remains a drug of choice for the treatment of MRSA and multidrug resistant Staphylococcus aureus infections.
\end{abstract}

Keywords: Staphylococcus aureus, methicillin resistance, nosocomial infections, vancomycin
Volume 2 Issue 2 - 2015

\author{
Obianuju Onelum, Babatunde Odetoyin, \\ Anthony Onipede, Adesola Oyelese \\ Department of Medical Microbiology and Parasitology, Obafemi \\ Awolowo University lle-Ife, Nigeria
}

Correspondence: Babatunde Odetoyin, Department of Medical Microbiology and Parasitology, Faculty of Basic Medical Sciences, Obafemi Awolowo University lle-lfe, Osun State, Nigeria, Tel +234803 696 8027, Email odetoyin@yahoo.com

Received: January 13, 2015 | Published: April 15, 2015
Abbreviations: MRSA, methicillin-resistant Staphylococcus aureus; CDC, center for disease control and prevention; OAUTHC, Obafemi Awolowo university teaching hospitals complex; STI, sexually transmitted infections; GOPD, general out-patient department; ENT, ear, nose and throat; TSA, tryptone soya agar; CLSI, clinical laboratory and standard institute; MIC, minimum inhibitory concentration; VRSA, vancomycin-resistant Staphylococcus aureus

\section{Introduction}

Methicillin-resistant Staphylococcus aureus (MRSA) is a major problem worldwide causing hospital acquired infections and infections in the community. ${ }^{1}$ Healthy people may carry MRSA asymptomatically for long periods of time but patients with compromised immune system are at a significant greater risk of symptomatic infections. The spectrum of infections due to MRSA are manifold ${ }^{2,3}$ and are associated with worse outcome in addition to prolonged hospital stay, higher cost of treatment and increased mortality. ${ }^{4,5}$ MRSA prevalence varies with geographical location, type of hospital and the population studied. The Center for Disease Control and Prevention (CDC) reported that MRSA is the most frequently identified antimicrobial drug-resistant pathogen in the US causing about $10 \%$ of all Staphylococcus infections and more than $50 \%$ of health-care associated Staphylococcus infections. ${ }^{6}$ By 2012 , the percentage has increased to more than $34 \%$ of clinical isolates of $S$. aureus while in Europe 26\% was reported, and $45 \%$ in the western Pacific.?

In Nigeria and many developing countries of Africa, studies have shown that the incidence of MRSA has been on the increase $\mathrm{e}^{8-13}$ thereby increasing concerns because of the linked increase in morbidity and mortality rates. A previous study on the carriage of MRSA in Ile-Ife reported a $50 \%$ carrier rate of MRSA in the nasal cavity and hands of hospital Staff. ${ }^{14}$ This raises serious concerns about the possibility of transmission of MRSA outside the health care system and risk to patients. There is still paucity of current information on MRSA in patients in Africa and treatment options available compared to the developed world. Therefore, this study was designed to focus on patients to determine the prevalence of MRSA, associated risk factors and antimicrobial susceptibility profiles of MRSA isolates.

\section{Materials and methods}

\section{Study population}

This study was carried out at Obafemi Awolowo University Teaching Hospitals Complex (OAUTHC), Ile-Ife, south west of Nigeria. Ethical approval for the study was sought and obtained from the Ethics and Research Committee of Obafemi Awolowo University Teaching Hospitals Complex (OAUTHC), Ile-Ife. 


\section{Sample and data collection}

Two hundred and forty-six (246) clinical samples were collected between the months of August 2012 and February 2013 from both the outpatient clinics and the in-patient wards of the hospital. The various wards/clinics included in the study were the Medical (male and female), Surgical (male and female), Intensive Care Unit (I.C.U.), Orthopaedic, Children, Accident/Emergency, Antenatal, Surgical outpatient, Neonatal, Sexually Transmitted Infections (STI) clinic, General Out-Patient Department (GOPD) and Ear, Nose and Throat (ENT) clinic. The clinical samples included urine, blood, semen, urethral swab, high vaginal swab, endocervical swab, wound swabs and wound biopsy, pus and wound exudate, ascitic fluid, catheter tips, sputum and stool. All were transported to the medical microbiology and parasitology laboratory in sterile containers for processing. Patients data consisted of age, gender, ward and diagnosis were collected using patients data card.

\section{Isolation and Identification of Staphylococcus aureus strains}

Each specimen was inoculated on Mannitol Salt Agar (Oxoid, England) and incubated aerobically at $37^{\circ} \mathrm{C}$ for 24 hours. Tiny yellowish colonies were picked and subcultured to nutrient agar (Oxoid, England), incubated aerobically at $37^{\circ} \mathrm{C}$ overnight and observed for morphological and cultural characteristics. All colonies typical of $S$. aureus morphologically were Gram stained. Additional confirmatory tests that included catalase test, coagulase tests and DNase test were done for all the isolates using standard microbiological methods. All isolates that were Gram-positive cocci, catalase, coagulase and DNase positive were considered as $S$. aureus. Representative and well separated colonies confirmed to be $S$. aureus were picked and stored in Tryptone Soya Agar (TSA) (Oxoid, England) for further investigation.

\section{Screening for methicillin resistance}

All isolates of $S$. aureus were screened for methicillin resistance using cefoxitin by disc diffusion method according to CLSI guidelines. The diameter of zone of inhibition of each isolate was measured and resistance was estimated by comparing with Clinical Laboratory and Standard Institute (CLSI) interpretative chart. ${ }^{15}$

\section{Antibiotic susceptibility testing}

Antimicrobial susceptibility testing for the isolates was performed by the Kirby-Bauer disc diffusion technique on Mueller Hinton agar (CM0337) (Oxoid, England) according to the guidelines set by CLSI (CLSI, 2009). Six antimicrobial agents which included oxacillin $(\mathrm{OX})(1 \mu \mathrm{g})$, linezolid (LZD) $(30 \mu \mathrm{g})$, chloramphenicol (C) $(30 \mu \mathrm{g})$, gentamicin $(\mathrm{CN})(30 \mu \mathrm{g})$, clindamycin (DA) $(2 \mu \mathrm{g})$ and cefotaxime $(30 \mu \mathrm{g})$ were tested against each isolate of $S$. aureus. The zones produced by each antibiotic were measured using a ruler to the nearest millimeter according to Clinical Laboratory and Standard Institute reference values. ${ }^{15}$

\section{Minimum inhibitory concentration (MIC) determination}

Minimum inhibitory concentration (MIC) of the ten multi drug resistant MRSA isolates that showed intermediate results for vancomycin by disc diffusion tests was determined using the MICEvaluation test kit according to CLSI guidelines. ${ }^{15}$

\section{Statistical analysis}

The Chi square $\left(\chi^{2}\right)$ test, Fisher's exact test and odd ratio (OR) (two tailed) were performed using SPSS statistical software (version 15) (Chicago, IL, USA) to determine the statistical significance of the data. All reported p-values were two-sided and a p-value of less than or equal to 0.05 was considered to be statistically significant

\section{Results}

\section{Staphylococcus aureus isolated from different wards and specimens}

A total of $102 S$. aureus strains were isolated and characterised from 246 clinical specimens. The highest number of $S$. aureus isolated was from the GOPD $(23,22.5 \%)$, followed by the surgical outpatient clinic $(19,18.6 \%)$ and the orthopaedic ward $(17,16.7 \%)$. Specimens from the neonatal ward and sexually transmitted infection (STI) clinic yielded the lowest frequency of $S$. aureus with $1(0.9 \%)$ and $2(2 \%)$ respectively (Table 1). Of all the 246 clinical specimens examined, wound swab yielded the highest frequency of $S$. aureus isolated 58 $(56.9 \%)$ followed by $28(27.5 \%)$. The lowest frequency of $S$. aureus isolated $1(0.98 \%)$ was found in stool samples (Table 2).

Table I Distribution of S. aureus and MRSA from patients at the different wards/units

\begin{tabular}{|c|c|c|c|}
\hline \multirow{2}{*}{ Wards } & $\begin{array}{l}\text { No of } \\
\text { specimen (\%) }\end{array}$ & $\begin{array}{l}\text { S. aureus } \\
\text { isolated (\%) }\end{array}$ & MRSA (\%) \\
\hline & $n=246$ & $n=102$ & $n=4 I$ \\
\hline In-patient wards & $183(74.4)$ & $73(71.6)$ & $30(73.2)$ \\
\hline $\begin{array}{l}\text { Accident/ } \\
\text { emergency }\end{array}$ & $13(5.6)$ & $6(5.9)$ & $0(0)$ \\
\hline Medical wards & $20(8)$ & $6(5.9)$ & I (2.4) \\
\hline Surgical wards & $9(3.6)$ & $6(5.9)$ & $0(0)$ \\
\hline $\begin{array}{l}\text { Orthopaedic } \\
\text { ward }\end{array}$ & $18(7.2)$ & $17(16.7)$ & II (26.8) \\
\hline Antenatal ward & $31(12.4)$ & $6(5.9)$ & $5(12.2)$ \\
\hline $\begin{array}{l}\text { Surgical } \\
\text { outpatient clinic }\end{array}$ & $61(25)$ & $19(18.6)$ & $9(21.9)$ \\
\hline $\begin{array}{l}\text { Intensive care } \\
\text { unit }\end{array}$ & $12(4.8)$ & $8(7.8)$ & $3(7.3)$ \\
\hline Neonatal wards & $5(2)$ & I (0.98) & I (2.4) \\
\hline Children ward & $14(5.7)$ & $4(3.9)$ & $0(0)$ \\
\hline $\begin{array}{l}\text { Outpatient } \\
\text { clinics }\end{array}$ & $63(25.6 \%)$ & $29(28.4)$ & II (26.8) \\
\hline GOPD & $55(22)$ & $23(22.5)$ & $10(24.9)$ \\
\hline STI & $4(1.6)$ & $2(1.96)$ & $0(0)$ \\
\hline ENT & $4(1.6)$ & $4(3.9)$ & I (2.4) \\
\hline
\end{tabular}

GOPD, general outpatient department; STI, sexually-transmitted infection clinic; ENT, ear nose and throat clinic 
Table 2The Frequency of S. aureus and MRSA from different clinical specimens

\begin{tabular}{|c|c|c|c|}
\hline Clinical & $\begin{array}{l}\text { No of } \\
\text { specimen (\%) }\end{array}$ & $\begin{array}{l}\text { Staphylococcus } \\
\text { aureus (\%) }\end{array}$ & MRSA (\%) \\
\hline & $n=246$ & $n=102$ & $n=4 I$ \\
\hline Urine & II 7 (47.6) & $28(27.5)$ & $10(24.4)$ \\
\hline Stool & $\mathrm{I}(0.4 \mathrm{I})$ & I (0.98) & $0(0)$ \\
\hline Wound swab & $69(28.0)$ & $58(56.9)$ & $26(63.4)$ \\
\hline Aspirates/pus & $12(4.9)$ & $4(3.9)$ & $2(4.9)$ \\
\hline $\begin{array}{l}\text { Urogenital } \\
\text { swabs }\end{array}$ & $37(15.0)$ & $8(7.8)$ & $2(4.9)$ \\
\hline Sputum & I (0.4I) & I (0.98) & $0(0)$ \\
\hline Blood & $9(3.7)$ & $2(1.96)$ & $\mathrm{I}(\mathrm{I} .8)$ \\
\hline
\end{tabular}

\section{Methicillin-resistant Staphylococcus aureus (MRSA)} isolated

A total of 41 (40.2\%) methicillin resistant S. aureus (MRSA) were detected from 102 S. aureus isolates tested. Thirty (73.2\%) of the $S$. aureus that were methicillin-resistant were obtained from inpatients and considered hospital-associated while eleven $(26.8 \%)$ were from outpatients (GOPD) and considered community-associated. The highest prevalence of MRSA was found in the orthopaedic ward 11 (26.8\%) followed by the general outpatient department $10(24.4 \%)$ and the surgical outpatient clinic $9(22 \%)$ while low prevalence were found in the neonatal ward $1(2.5 \%)$, medical ward $1(2.5 \%)$ and ENT ward $1(2.5 \%)$. No MRSA was isolated from the accident and emergency ward, children ward and the STI clinic (Table 1). As shown in Table 2, 26 (63.4\%) MRSA was isolated from wound swabs, $10(24.4 \%)$ from urine and two (4.9\%) from aspirates/pus and urogenital swabs.

\section{Risk factors associated with MRSA infections}

Different risk factors were associated with MRSA infections. These included, age, gender, ward and diagnosis as shown in Table 3. Thirty-nine $(41.5 \%)$ MRSA was isolated from adults and two $(25 \%)$ from children. There was no significant difference in MRSA isolation between adults and children $\left(\chi^{2}=0.834 ; \mathrm{P}=0.361\right)$. All the patients from whom MRSA were isolated were divided into six age categories. The highest isolation rate of MRSA was found in patients that were in the age range of 21-40 years while the lowest rate was seen in the patients that are below 20 years of age (Figure 1). Of a total of 41 MRSA isolated, nineteen $(37.3 \%)$ were isolated from male and twenty-two (43.1\%) from female. Thirty $(41.1 \%)$ isolates were hospital-associated MRSA while eleven (37.9\%) were communityassociated methicillin-resistant Staphylococcus aureus. There was no significant difference in the isolation of MRSA between male and female $\left(\chi^{2}=0.367 ; \mathrm{P}=0.545\right)$, and between samples from the hospital and the community $\left(\chi^{2}=0.086 ; \mathrm{P}=0.769\right)$ (Table 3$)$. Of all the wards from which MRSA was isolated in this study, MRSA was eight times likely to be isolated in antenatal ward $(\mathrm{OR}=8.33$; $\mathrm{CI}=0.8-400.53$; $\mathrm{p}=0.037$ ) and three times likely to be isolated from orthopaedic ward $(\mathrm{OR}=3.36 ; \mathrm{CI}=1.01-12.09 ; \mathrm{p}=0.031)$ compared to the rest of the wards. No clinical diagnosis was significantly associated with MRSA infection $(\mathrm{P}>0.05)$.

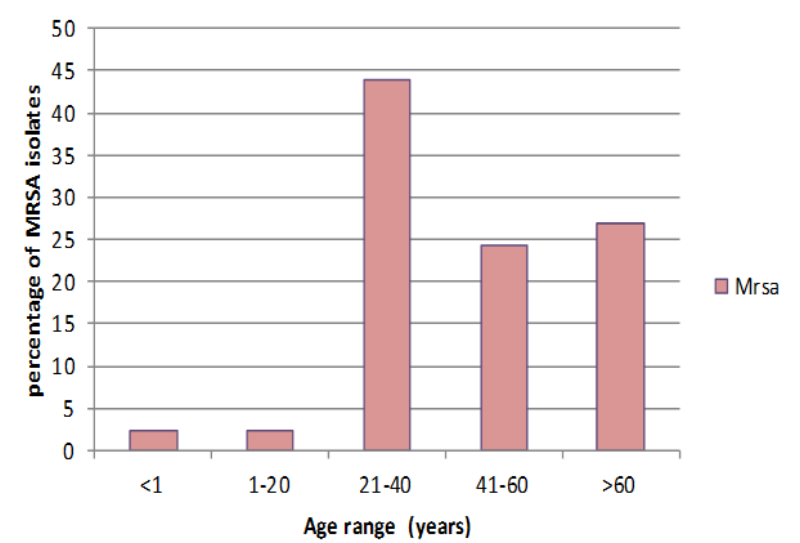

Figure I Age distribution of patients in whom MRSA were detected.

Table 3 Risk factors associated with MRSA infections

\begin{tabular}{|c|c|c|c|}
\hline \multirow{3}{*}{ Risk factor } & \multicolumn{3}{|c|}{ Staphylococcus aureus isolates $(n=102)$} \\
\hline & MRSA (\%) & MSSA (\%) & $P$ value \\
\hline & $n=41$ & $n=61$ & \\
\hline \multicolumn{4}{|l|}{ Age } \\
\hline Adult & $39(4 \mid .5)$ & $55(58.5)$ & $P=0.20762 *$ \\
\hline Children & $2(25)$ & $6(75)$ & \\
\hline \multicolumn{4}{|l|}{ Sex } \\
\hline Male & $19(37.3)$ & $32(62.7)$ & $\chi 2=0.367 ; P=0.545$ \\
\hline Female & $22(43.1)$ & $29(56.9)$ & \\
\hline \multicolumn{4}{|l|}{ Location } \\
\hline Community & II (37.9) & $18(62.1)$ & $\chi 2=0.086 ; P=0.769$ \\
\hline Hospital & $30(4 I . I)$ & $43(58.9)$ & \\
\hline \multicolumn{4}{|l|}{ Wards } \\
\hline \multirow[t]{2}{*}{$\begin{array}{l}\text { Orthopaedic } \\
\text { ward }\end{array}$} & II (26.8) & $6(9.8)$ & O.R.=3.36; P=0.03I; \\
\hline & & & C.I. $=I .01$ to 12.09 \\
\hline \multirow[t]{2}{*}{$\begin{array}{l}\text { Intensive care } \\
\text { unit }\end{array}$} & $3(7.3)$ & $5(8.2)$ & O.R.= 0.88: $P=1.000$ \\
\hline & & & C.I. $=0.13$ to 4.86 \\
\hline \multirow[t]{2}{*}{ Antenatal } & $5(12.2)$ & I (I.6) & O.R.=8.33; P = 0.037; \\
\hline & & & C.I. $=0.8$ to 400.53 \\
\hline \multirow[t]{2}{*}{ SOP } & $9(22)$ & $10(16.4)$ & $O . R=I .43: P=0.605$ \\
\hline & & & C.I. $=0.46$ to 4.40 \\
\hline \multirow[t]{2}{*}{ GOPD } & $10(24.4)$ & $13(21.3)$ & O.R.= I.19; P = 0.810; \\
\hline & & & C.I. $=0.4 \mathrm{I}$ to 3.36 \\
\hline \multicolumn{4}{|l|}{ Diagnosis } \\
\hline \multirow[t]{2}{*}{ Burn wounds } & $2(4.9)$ & $5(8.2)$ & O.R. $=0.57 ; P=0.699 ;$ \\
\hline & & & C.I. $=0.05$ to 3.75 \\
\hline $\begin{array}{l}\text { Wounds/ } \\
\text { ulcers/abcesses }\end{array}$ & $7(17.1)$ & $13(2 \mid .3)$ & O.R. $=0.76 ; P=0.800$ \\
\hline
\end{tabular}




\begin{tabular}{|c|c|c|c|}
\hline \multirow{3}{*}{ Risk factor } & \multicolumn{3}{|c|}{ Staphylococcus aureus isolates $(\mathrm{n}=102)$} \\
\hline & MRSA (\%) & MSSA (\%) & P value \\
\hline & $n=4 \mid$ & $n=61$ & \\
\hline & & & C.I. $=0.23$ to 2.32 \\
\hline \multirow[t]{2}{*}{ Sepsis } & $5(12.1)$ & $2(3.3)$ & O.R. $=4.10 ; P=0.114$ \\
\hline & & & C.I. $=0.62$ to 44.53 \\
\hline \multirow[t]{2}{*}{ Osteomyelitis } & $4(9.8)$ & $4(6.6)$ & $O . R=1.54 ; P=0.71 \mathrm{I}$ \\
\hline & & & C.I. $=0.27$ to 8.78 \\
\hline \multirow[t]{2}{*}{ Surgical wound } & $8(19.5)$ & $6(9.8)$ & $O . R .=2.22 ; P=0.240 ;$ \\
\hline & & & C.I. $=0.61$ to 8.4 \\
\hline
\end{tabular}

*Fisher's exact test; $P \leq 0.05$ is significant; $\chi^{2}$, chi square; O.R, odd ratio; C.I, confidence interval

\section{Antimicrobial resistance profiles of $S$. aureus and MRSA isolates}

Among the $102 \mathrm{~S}$. aureus isolated, high rates of resistance were recorded for cefotaxime $(81,79.4 \%)$ and oxacillin $(67,65.7 \%)$. However, few isolates were resistant to linezolid 9 (8.8\%) (Table 4). A comparison of antimicrobial resistance profiles of MRSA and MSSA isolates showed that MRSA isolates were more commonly resistant to gentamicin $(\mathrm{p}=0.0001)$, oxacillin $(\mathrm{p}=0.0001)$, and cefotaxime $(\mathrm{p}=0.0002)$ compared to MSSA isolates. Eleven (10.8\%) isolates of S. aureus were resistant to one type of antibiotics, 27 (26.5\%) were resistant to two types of antibiotics and $53(52 \%)$ were multi-drug resistant (resistant to three or more different types of antimicrobial drugs). In addition, MRSA isolates were more commonly resistant to three or more types of antibiotics than MSSA isolates ( $\mathrm{p}=0.0001$ ) (Table 5).

Table 4 Comparison of antimicrobial resistance profiles of MRSA and MSSA isolates

\begin{tabular}{|c|c|c|c|c|}
\hline \multirow{3}{*}{$\begin{array}{l}\text { Antimicrobial } \\
\text { agents }\end{array}$} & \multicolumn{2}{|c|}{$\begin{array}{l}\text { Staphylococcus aureus } \\
\text { isolates }\end{array}$} & \multirow{2}{*}{ Total } & \multirow{2}{*}{$P$ value } \\
\hline & MRSA (\%) & MSSA (\%) & & \\
\hline & $n=4 \mid$ & $n=61$ & $n=102$ & \\
\hline Cefoxitin & $4 \mathrm{I}(100)$ & $0(0)$ & $4 \mid(40.2)$ & $0.0001 *$ \\
\hline Oxacillin & $40(97.5)$ & $27(44.3)$ & $67(65.7)$ & 0.0001 \\
\hline Linezolid & $3(7.31)$ & $6(9.84)$ & $9(8.8)$ & 0.66 \\
\hline Chloramphenicol & $16(39)$ & $13(2 \mid .3)$ & $29(28.4)$ & 0.052 \\
\hline Gentamicin & $19(46.3)$ & $9(14.8)$ & $28(27.5)$ & 0.0001 \\
\hline Clindamycin & $22(53.7)$ & $28(45.9)$ & $50(49.0)$ & 0.442 \\
\hline Cefotaxime & $40(97.5)$ & $4 \mid(67.2)$ & 81 (79.4) & 0.0002 \\
\hline
\end{tabular}

*Pearson's chi square: $\mathrm{P} \leq 0.05$ is significant
Table 5 Multi-drug resistance profiles of MRSA and MSSA to different number of antibiotics

\begin{tabular}{|c|c|c|c|c|}
\hline \multirow{3}{*}{$\begin{array}{l}\text { No of } \\
\text { antibiotics }\end{array}$} & \multicolumn{2}{|c|}{ No of resistant Isolates } & \multirow{2}{*}{ Total } & \multirow{2}{*}{$P$ value } \\
\hline & MRSA (\%) & MSSA (\%) & & \\
\hline & $n=4 I$ & $n=61$ & $n=102$ & \\
\hline I & $0(0)$ & II (I8) & II (I0.8) & $0.011^{*}$ \\
\hline 2 & $9(22)$ & $18(29.5)$ & $27(26.5)$ & 0.396 \\
\hline 3 & I3 (3I.7) & $10(16.4)$ & $23(22.5)$ & 0.07 \\
\hline 4 & $9(22)$ & $6(9.8)$ & $15(14.7)$ & 0.09 \\
\hline 5 & $5(12.1)$ & $2(3.3)$ & $7(6.7)$ & 0.081 \\
\hline 6 & $4(9.8)$ & $2(3.3)$ & $6(5.9)$ & 0.35 \\
\hline 7 & I (2.4) & $2(1.6)$ & $3(2.9)$ & I \\
\hline$>3$ & $32(78)$ & $21(34.4)$ & $53(52.0)$ & 0.0001 \\
\hline
\end{tabular}

*Pearson's chi square: $\mathrm{P} \leq 0.05$ is significant.

\section{Minimum inhibitory concentration}

All the 10 MRSA isolates were susceptible to vancomycin (256$0.015 \mu \mathrm{g} / \mathrm{ml}$ ) with MIC values ranging from 2.1 to $0.12 \mu \mathrm{g} / \mathrm{ml}$.

\section{Discussion}

Results of this study indicated that the prevalence of hospitalassociated MRSA isolates was $73.2 \%$. Though the prevalence obtained in this study was higher than the prevalence of $11 \%$ reported in earlier studies in Nigeria by Shittu et al., ${ }^{16}$ in Ile-Ife, $28.6 \%$ by Nwankwo et al., ${ }^{17}$ in Kano, $34.7 \%$ by Taiwo et al., ${ }^{18}$ in Ilorin and $11 \%$ by Obasuyi ${ }^{19}$ in Benin-city, this observed differences may be due to different population studied, the antibiotic consumption pattern and the periods when the studies were conducted. The same reasons can also be advanced for the studies reported by Jacobus et al., ${ }^{20}$ in USA 58\%; Kateete et al., ${ }^{21}$ in Uganda 46\% and Olowe et al., ${ }^{11}$ in Oshogbo $47.8 \%$ that reported higher prevalence value than we reported. Other plausible reasons for the observed differences in these studies include differences in the laboratory methods employed to screen MRSA as well as differences in sampling and culture techniques. ${ }^{22}$

MRSA were significantly isolated from patients in the orthopaedic wards. This may be because orthopaedic patients usually stay longer in the hospital while waiting for their fractures to heal before they are discharged. Although, a limitation of the present study is the inability to use molecular typing techniques to establish transmission of strain between patients and staff on one hand and the community on the other. However, we can safely speculate that such a transmission is likely ongoing as hospital staff has shown to be carriers of MRSA in significant numbers ${ }^{14}$ and efficient transmitters through the hands when infection control principles are not strictly adhered to. Other authors who have reported different rates of MRSA in institutionalized settings in support of our findings include Fadeyi et al.,23 that reported MRSA rate of $52.5 \%$ in a similar orthopaedic ward in a Nigerian hospital and Onanuga et al. ${ }^{10}$ who reported a high prevalence rate of MRSA among pregnant women in Abuja as we observed in the antenatal clinic in this study.

The assessment of the antimicrobial susceptibility profile of the MRSA and MSSA isolates showed high rates of resistance to clindamycin and cefotaxime. The rates of resistance were lower to 
chloramphenicol and gentamicin which was contrary to the high resistance of $58 \%$ reported by Kalsoom and Hameed in $2006 .{ }^{24} \mathrm{~A}$ comparison of the multi-drug resistance profiles of MRSA and MSSA to different number of antibiotics showed no significant difference except to three or more antibiotics $(\mathrm{p}=0.0001)$ suggesting that MRSA isolates are more likely to be resistant to three or more antimicrobial agents than methicillin-sensitive Staphylococcus aureus (MSSA) isolates. The presence of the mecA gene in MRSA is responsible for making MRSA isolates resistant to more antibiotics as compared to MSSA isolates.

All the ten multidrug $S$. aureus isolates were sensitive to vancomycin with values ranging from $0.12-2.1 \mu \mathrm{g} / \mathrm{ml}$ which is comparable to findings of Kan. ${ }^{25}$ This indicates that though reduced susceptibility of Staphylococcus aureus to vancomycin have been reported in Japan and USA, cases are still rare in Nigeria. ${ }^{26}$ This study showed that MRSA and multidrug resistant strains of $S$. aureus in this setting are susceptible to vancomycin (which is the first line treatment of choice for MRSA). Decreasing vancomycin susceptibilities, increasing incidence of MRSA infections and emergence of vancomycin-intermediate and vancomycin-resistant strains leading to clinical failures have made it necessary to re-evaluate the options for the treatment of serious MRSA infections. ${ }^{27}$ Consideration of alternative drugs for the treatment of MRSA infections is warranted when deciding upon appropriate antimicrobial therapy. Despite increasing reports of vancomycin-resistant Staphylococcus aureus (VRSA) worldwide, they are still very few reports in Nigeria. ${ }^{26}$

\section{Conclusion}

This study has established that MRSA is a major pathogen in both hospital based and community acquired infection in our setting. The implication is that it will be a major consideration of the decision process when therapeutic options are considered for a patient. More studies are clearly needed particularly in all regions of Africa particularly Nigeria and other developing poor-resourced areas to determine the current epidemiology outlook of this increasingly important nosocomial and community-acquired pathogen and the various risk factors that might be associated with MRSA infections.

\section{Acknowledgments}

We thank all the members of staff of Obafemi Awolowo University Teaching Hospitals Complex for their cooperation in getting the isolates that were used in this study.

\section{Conflicts of interest}

Authors declare that there is no conflict of interest.

\section{References}

I. Baldan R, Tassan Din C, Semeraro G, et al. Severe community-onset infections in healthy individuals caused by community-acquired MRSA in an Italian teaching hospital, 2006-2008. J Hosp Infect. 2009;72(3):27I 273.

2. Tenover FC, Gaynes RP.The Epidemiology of Staphylococcal Infections. In: Fischetti VA, et al. (Eds.), Gram Positive pathogens. American Society for microbiology: USA; 2000. 4I4-42I p.

3. Holmes A, Ganner M, McGuane S, et al. Staphylococcus aureus isolates carrying Panton-Valentine leucocidin genes in England and Wales: frequency, characterization, and association with clinical disease. J Clin Microbiol. 2005;43(5):2384-2390.
4. Zahar JR, Clech C, Tafflet M, et al. Outcomerea Study Group. Is methicillin resistance associated with a worse prognosis in Staphylococcus aureus ventilator-associated pneumonia? Clin Infect Dis. 2005;4 I(9): | 224- I23 |

5. Shorr AF, Tabak YP, Gupta $\mathrm{V}$, et al. Morbidity and cost burden of methicillin-resistant Staphylococcus aureus in early onset ventilatorassociated pneumonia. Crit Care. 2006; I0(3):R97.

6. Centre for Disease Control (CDC). MRSA infections: people at risk of acquiring MRSA infections; 2010.

7. Stefani S, Chung DR, Lindsay JA, et al. Methicillin-resistant Staphylococcus aureus (MRSA): global epidemiology and harmonisation of typing methods. Int J Antimicrob Agents. 20 I2;40(4):273-282.

8. Kesah C, Ben Redjeb S, Odugbemi TO, et al. Prevalence of methicillinresistant Staphylococcus aureus in eight African hospitals and Malta. Clin Microbiol Infect. 2003;9(2): I53-I56.

9. Taiwo SS, Onile BA,Akanbi AA. Methicillin-resistant Staphylococcus aureus isolates in Ilorin, Nigeria. African Journal of Clinical and Experimental Microbiology. 2004;5(2): I89- 197.

10. Onanuga A, Oyi AR, Onaolapo JA. Prevalence and susceptibility pattern of methicillin resistant Staphylococcus aureus isolates among healthy women in Zaria, Nigeria. African Journal of Biotechnology. 2005;4(I I): | 32 |- I 324

II. Olowe OA, Eniola KIT, Olowe RA, et al.Antimicrobial susceptibility and Beta-lactamase detection of methicillin-resistant Staphylococcus aureus in Osogbo, Southwest Nigeria. Nature and Science. 2007;5(3):44-48.

12. Azeez-Akande O. Global trend of methicillin-resistant Staphylococcus aureus and emerging challenges for control. African Journal of Clinical and Experimental Microbiology. 20 I0; I I (3): I50-I58.

13. Okon KO, Shittu AO, Usman H, et al. Epidemiology and Antibiotic Susceptibility Pattern of Methicillin-Resistant Staphylococcus aureus recovered from Tertiary Hospitals in North-eastern, Nigeria. Journal of Medicine and Medical Sciences. 20I3;4(5):214-220.

14. Onipede $A O$, ljadunola $K T$, Faponle $A F$, et al. $A$ preliminary report of methicillin-resistant Staphylococcus aureus carriage among hospital staff in critical care units in Ile-Ife. Nigerian Journal of Health sciences. 2007;8(I):30-34

15. Clinical and Laboratory Standards Institute (CLSI). Performance Standards for antimicrobial susceptibility testing; I 5 th informational supplement MI00-SI 5; 2009.

16. Shittu AO, Lin J, Kolawole DO. Antimicrobial susceptibility patterns of Staphylococcus aureus and characterization of MRSA in Southwestern Nigeria. Wounds. 2006; I8(4):77-84.

17. Nwankwo EOK,Abdulhadi S, Magagi A, et al. Methicillin-resistant Staphylococcus aureus and their antibiotic sensitivity pattern in Kano, Nigeria. African Journal of Clinical and Experimental Microbiology. $2010 ;$ II (I):129-I36.

18. Taiwo SS, Bamidele M, Omonigbehin EA, et al. Molecular epidemiology of methicillin resistant Staphylococcus aureus in Ilorin, Nigeria. West Afr J Med. 2005;24(2): 100-106.

19. Obasuyi O. Molecular identification of methicillin-resistant Staphylococcus aureus in Benin-city, Nigeria. Afr J Cln Exper Microbiol. $2013 ; 14(1): 1-4$.

20. Jacobus $\mathrm{CH}$, Lindsell CJ, Leach SD, et al. Prevalence and demographics of methicillin-resistant Staphylococcus aureus in culturable skin and soft tissue infections in an urban emergency department. BMC Emerg Med. 2007;7:19. 
21. Kateete DP, Kimani CN, Katabazi FA, et al. Identification of Staphylococcus aureus: DNase and Mannitol salt agar improve the efficiency of the tube coagulase test. Ann Clin Microbiol Antimicrob. 2010;9:23-25.

22. Adesida SA,Abioye OA, Bamiro BS, et al. Associated risk factors and pulsed field gel electrophoresis of nasal isolates of Staphylococcus aureus from medical students in a tertiary hospital in Lagos, Nigeria. Braz J Infect Dis. 2007; I I ( I):63-69.

23. Fadeyi A, Bolagi BO, Oyedepo OO, et al. Methicillin-resistance Staphylococcus aureus carriage amongst healthcare workers of the critical care units in a Nigerian hospital. American Journal of Infectious Diseases. 2010;6(I): 18-23.
24. Kalsoom F, Hameed A. Resistance pattern of clinical isolates of Staphylococcus aureus against five groups of antibiotics. Journal of Research Science. 2006; 17:19-26.

25. Kan LP, Lin JC, Chiu SK, et al. Methicillin-resistant Staphylococcus aureus bacteraemia in hemodialysis and nondialysis patients.J Microbiol Immunol Infect. 20I4;47(I): I 5-22.

26. Taiwo SS, Bamigboye TB, Odaro O, et al.Vancomycin intermediate and high level vancomycin resistant Staphylococcus aureus clinical isolates in Osogbo. Microbiology Research. 201 I;2(1):22-25.

27. Howden BP, Peleg AY, Stinear TP.The evolution of vancomycin intermediate Staphylococcus aureus (VISA) and heterogenous-VISA. Infect Genet Evol. 2013;21:575-582. 